\title{
Iridium-Based Catalysts for the Ethanol Electrooxidation in Acidic Media
}

\author{
Fabiano R. P. da Silva, ${ }^{a}$ Luiz C. Silva-Junior, ${ }^{a}$ Giuseppe A. Camara ${ }^{a}$ and \\ Martha Janete Giz ${ }^{\circledR * a}$ \\ ${ }^{a}$ Instituto de Química, Universidade Federal de Mato Grosso do Sul, \\ CP 549, 79070-900 Campo Grande-MS, Brazil
}

\begin{abstract}
Herein we sinthesize and investigate Ir-based nanocatalysts (dispersed in carbon) in different atomic compositions combining two ( $\mathrm{IrRh}$ ) and three metals ( $\mathrm{IrRhSn}$ ). These materials were evaluated towards the ethanol electrooxidation in acidic electrolyte in presence of three ethanol concentrations using cyclic voltammetry, while the species produced during the reaction were monitored by in situ Fourier transform infrared spectroscopy (FTIR). Results show that IrRh binary electrocatalysts are selective to the production of $\mathrm{CO}_{2}$ from ethanol, but the catalytic activity is poor. This finding is interpreted in terms of a slow adsorption of ethanol that is assumed to be the rate determining step during the electrooxidation of the alcohol. Ternary catalysts, in turn, present higher electrooxidation currents and anticipate the production of $\mathrm{CO}_{2}$. However, the selectivity towards the $\mathrm{CO}_{2}$ pathway is lost and the higher catalityc activity is justified by a growing production of acetic acid, illustrating the influence of Sn on the eletrooxidation of ethanol.
\end{abstract}

Keywords: ethanol electrooxidation, electrocatalysis, IrRhSn nanoparticle, in situ FTIR

\section{Introduction}

Platinum and Pt-based alloys are the most commonly used catalysts in both anodic and cathodic fuel cell reactions due to their ability to adsorb and dissociate small organic molecules. ${ }^{1-6}$ However, Pt-based catalysts are neither the best materials to electrooxidize organic molecules nor to drive the electrochemical reactions to some desired pathways, constituting a major constraint for the commercialization of this technology.,8 Thus, the development of alternative electrocatalysts with higher activity and selectivity for the electrooxidation of organic molecules, as for the ethanol oxidation reaction (EOR) is vital for the implementation of proton-exchange membrane fuel cell (PEMFC) technology.

In this context, Gupta et al. ${ }^{9}$ studied the behavior of ethanol oxidation in Pt and PtRh electrodeposits. The authors suggested that a small addition of $\mathrm{Rh}$ increases the ability of $\mathrm{Pt}$ to dissociate $\mathrm{C}-\mathrm{C}$ bonds, improves the selectivity for $\mathrm{CO}_{2}$ production and anticipates the onset potential of oxidation. ${ }^{9}$ The role of $\mathrm{Rh}$ is associated to a promotion of ethanol hydrogenation, which facilitates $\mathrm{C}-\mathrm{C}$ bond splitting, providing $\mathrm{Rh}$ is present in minor amounts. However, the authors argue that the same effect can be detrimental for the

*e-mail: janete.giz@ufms.br ethanol electrooxidation because a $\mathrm{Rh}$ surface excess $(65 \%$ in atoms) associated with the strong adsorption of hydrogen on this metal prevents the adsorption of the alcohol, probably by the lack of free superficial sites. ${ }^{9}$ Bergamaski et al. ${ }^{10}$ and de Souza et al. ${ }^{11}$ also observed that with the addition of $\mathrm{Rh}$, there is an improvement in the oxidation efficiency of ethanol to $\mathrm{CO}_{2}$, but the global current density decreases. According to the authors, to circumvent this drawback in EOR, a third element would have to be added. ${ }^{11}$

Lamy and co-workers ${ }^{12}$ studied the ethanol electrooxidation in Pt and PtSn catalysts and observed that the addition of Sn not only anticipates the onset potential of oxidation but there is also a gain in current densities compared to pure Pt. According to the authors, the presence of $\mathrm{Sn}$ in the PtSn catalyst facilitates the adsorption of water, providing $\mathrm{OH}$ species for the $\mathrm{CO}$ oxidation, which is an important intermediate generated during the adsorption of ethanol on Pt. ${ }^{12}$

In a previous work, we demonstrated that the addition of Sn also showed good results on ternary catalysts based on $\mathrm{Pt}(\mathrm{PtRh} / \mathrm{C}$ and $\mathrm{PtRhSn} / \mathrm{C}) .{ }^{13}$ Based on those results, the presence of Sn apparently facilitates both oxidation and adsorption steps of ethanol, resulting in a higher electrocatalytic activity. ${ }^{13}$ The anticipation of the ethanol oxidation potential was also observed by Ribeiro et al. ${ }^{14}$ on carbon supported $\mathrm{PtIr} / \mathrm{C}, \mathrm{PtSn} / \mathrm{C}$ and $\mathrm{PtSnIr} / \mathrm{C}$ catalysts. 
The authors observed that the ethanol oxidation starts at values below $0.25 \mathrm{~V}$ (reversible hydrogen electrode (RHE)) on these catalysts. ${ }^{14}$

The literature reports that iridium (Ir) associated with several other metals ( $\mathrm{Se}, \mathrm{V}, \mathrm{Co}, \mathrm{Sn}, \mathrm{Pt}$ and $\mathrm{Rh}$ ) have shown encouraging results for EOR in fuel cells. ${ }^{15-20}$ However, the lack of structural and spectroscopic information for Ir-based systems hampers mechanistic interpretation and direct comparison with other well-characterized Pt-based catalysts for fuel cell reactions, as those cited in the previous paragraphs.

Iridium has advantageous properties such as: low oxygen permeability, good chemical stability and good electronic conductivity, corrosion resistance, high catalytic activity, ${ }^{21}$ high purity in the deposits and a better adhesion control in the substrate..$^{22}$

Ir has some chemical properties similar to those of $\mathrm{Pt}$ and previous works demonstrate that it presents catalytic activity for EOR, but without suffering $\mathrm{CO}$ poisoning. ${ }^{23}$ By using Ir/Pt supported on carbon, Tayal et al. ${ }^{24}$ suggest a positive effect on the catalytic activity for EOR when compared to pure Pt if small amounts of Ir are added. Cao et al. ${ }^{25}$ compared cyclic and linear voltammetries of $\mathrm{IrSn} / \mathrm{C}$ and $\mathrm{Pt} / \mathrm{C}$ and observed that EOR starts at smaller potentials and has higher currents in $\mathrm{IrSn} / \mathrm{C}$ than in $\mathrm{Pt} / \mathrm{C}{ }^{25}$

These studies show that Ir is a promising electrocatalyst for EOR. However, structural and spectroscopic information in Ir-based systems are scarce, which does not allow to establish what is the role played by Ir in EOR and prevents a molecular interpretation. In view of these premises, herein we study EOR in acidic medium on $\mathrm{IrRh} / \mathrm{C}$ and $\mathrm{IrRhSn} / \mathrm{C}$ nanoparticulate catalysts. The electrochemical characterization was performed by cyclic voltammetry while in situ Fourier transform infrared (FTIR) was conducted to monitor the species present in the neighborhood of the electrodes during the ethanol electrooxidation.

\section{Experimental}

Ir, $\mathrm{Rh}$ and $\mathrm{Sn}$ nanoparticles were prepared using the polyol method proposed by Fiévet et al. ${ }^{26}$ and Viau et al. ${ }^{27}$ During the synthesis, the masses of their respective salts ( $\mathrm{IrCl}_{3}, \mathrm{RhCl}_{3}$ and $\mathrm{SnCl}_{2}$, Sigma-Aldrich, St. Louis, MO, USA) were adjusted to generate atomic compositions of 70:30, 80:20 and 90:10 for IrRh binary catalysts and of 70:10:20 and 80:10:10 for the ternary ones (IrRhSn). Namely, the precursor salts were dispersed on Vulcan XC-72 carbon powder (Cabot, Inc., Boston, MA, USA) (20\% by mass of metal) in the presence of a solution of ethylene glycol/water (volume ratio of 3:1) and sonicated for $20 \mathrm{~min}$. After sonication, the dispersion was solubilized in water in the presence of polyvinylpyrrolidone (PVP) (Aldrich, PA, MM 40,000), and added to the flask, and then returned to the ultrasonic bath for another $10 \mathrm{~min}$. Afterwards, the mixture was heated to $140{ }^{\circ} \mathrm{C}$ on a magnetic stirrer/heater coupled to a condenser, under reflux for $1 \mathrm{~h}$. Subsequently, it was cooled to room temperature, and then centrifuged. At the end of the centrifugation, the excess of liquid was removed and the precipitate was washed thoroughly with ultrapure deionized water and centrifuged again for $30 \mathrm{~min}$. This procedure was repeated three more times. After centrifugation, the mixture was brought to the oven for $48 \mathrm{~h}$, and after drying, was triturated and packed in a suitable container.

Afterwards, the catalysts were fixed to a gold disk that served as support, by using the following procedure: a mixture containing $1 \mathrm{mg}$ of catalyst powder and $2 \mathrm{~mL}$ of isopropanol was prepared. This mixture was sonicated for $20 \mathrm{~min}$ to homogenize the distribution of the solid particulate. The resultant dispersion was applied onto the gold disk ( $10 \mathrm{~mm}$ of diameter) placed on a plate previously heated to $40{ }^{\circ} \mathrm{C}$. For the electrochemical experiments, $200 \mu \mathrm{L}$ of this dispersion were placed over the disk in four aliquots of $50 \mu \mathrm{L}$. Such fractioning allows the powder become more homogeneously distributed over the surface. After drying the dispersion, two aliquots of $50 \mu \mathrm{L}$ of a Nafion ${ }^{\circledR}$ solution (prepared by mixing $90 \mu \mathrm{L}$ of $\mathrm{Nafion}^{\circledR}$ in $20 \mathrm{~mL}$ of methanol) were applied over the film to guarantee good mechanical resistance. For the spectroelectrochemical experiments (FTIR), lower catalyst loads were used to prevent the excess of powder (that shows no reflectance) from affecting the quality of the FTIR signal. Hence, two aliquots of $25 \mu \mathrm{L}$ of the dispersion containing the catalyst were adopted for $50 \mu \mathrm{L}$ of Nafion ${ }^{\circledR}$.

For purposes of comparison, pure Ir surfaces were also used in the present work. They were obtained by potentiostatic electrodeposition through the reduction of $\mathrm{Ir}^{3+}$ (from $\left.\mathrm{IrCl}_{3}\right)$ in acid medium $\left(0.1 \mathrm{~mol} \mathrm{~L}^{-1} \mathrm{HClO}_{4}\right)$, applying a potential of $-0.268 \mathrm{~V}$ (RHE) for $30 \mathrm{~min}$, in an equipment Autolab PGSTAT 128N potentiostat from Metrom Autolab (Switzerland). Here it is noteworthy that we intended to establish a standard behavior of Ir in presence of ethanol, to which the binary and ternary catalysts could be compared, hence the choice of an electrodeposit. However, since features as particle size and the presence of low-coordination sites influence the electrocatalytic behavior of a surface, we are currently working on the design on Ir nanoparticles aiming to consider these aspects.

The atomic ratios of binary and ternary catalysts were estimated by the energy dispersive spectroscopy (EDS) 
analysis using a Noran System Six instrument (Thermo Scientific, Waltham, MA, USA) provided with a $\mathrm{Si}(\mathrm{Li})$ detector. The mean values were obtained from three points to each sample.

The materials were morphologically characterized by X-ray diffraction (XRD) in a Rigaku Ultima IV diffractometer (Texas, USA), using a scan rate of 1 degree $\min ^{-1}$ between 10 and 100 degrees in $2 \theta$.

Average size and shape of the nanoparticles were investigated by transmission electron microscopy (TEM) using a transmission electron microscope JEOL JEM 2100 (Boston, MA, USA) working at $200 \mathrm{kV}$. A $3 \mathrm{~mL}$ drop of the suspension containing the supported nanoparticles was deposited and dried under ambient conditions on a standard 400 mesh TEM grid. Afterwards, the nanoparticles were imaged.

Electrochemical experiments were carried out using a three-electrode electrochemical cell containing $0.1 \mathrm{~mol} \mathrm{~L}^{-1} \mathrm{HClO}_{4}$ as supporting electrolyte. Each surface was conditioned by cyclic voltammetry in the supporting electrolyte between 0.05 and $1.4 \mathrm{~V}$ for binary catalysts and between 0.05 and $0.9 \mathrm{~V}$ for ternary materials at a scan rate of $0.05 \mathrm{~V} \mathrm{~s}^{-1}$. This cycling protocol was used to minimize the interference of synthesis residues in the electrochemical response, as recently discussed for $\mathrm{Cu}_{2} \mathrm{O}$-based electrochemical sensors. ${ }^{28}$ Each catalyst was submitted to a few voltammetric cycles (typically 5 cycles were used). This number was sufficient for the voltammetric profiles to become superimposed (i.e., stable). Then, a CO stripping in each surface was performed as follows: the potential was kept at $0.05 \mathrm{~V}$ and carbon monoxide was admitted in the cell by bubbling the gas during $10 \mathrm{~min}$. Thereafter, non-adsorbed $\mathrm{CO}$ was eliminated from the solution by bubbling pure $\mathrm{N}_{2}$ for $10 \mathrm{~min}$ and cyclic voltammograms were recorded at $0.02 \mathrm{~V} \mathrm{~s}^{-1}$ in the potential range described above in order to estimate the electrochemical surface area of the electrodes. For this, it was assumed that the oxidation of a $\mathrm{CO}$ monolayer on Ir generates a charge density of $287.7 \mu \mathrm{C} \mathrm{cm}^{-2} .{ }^{29}$ All electrochemical results are normalized by the corresponding electrochemical surface areas (ECSA) obtained by the CO stripping protocol. An RHE prepared with the same electrolyte solution used in the experiments was used as reference electrode. As a counter electrode, a platinum mesh was used and the polycrystalline gold disk, on which the electrocatalysts were fixed, was used as the support for the working electrode, as described in the previous section.

In situ FTIR experiments were performed in the infrared reflection absorption configuration (IRRAS) in a three-electrode spectroelectrochemical cell fitted to a planar $\mathrm{CaF}_{2}$ window. For the acquisition of spectra, we used a FTIR spectrometer (Hartmann \& Braun, model MB-100, Quebec, Canada) coupled to an MCT (mercury cadmium telluride) detector cooled with liquid nitrogen. The spectral resolution was set to $8 \mathrm{~cm}^{-1}$. Reflectance spectra were calculated as the ratio $\left(R / R_{0}\right) \times 100$, where $\mathrm{R}_{0}$ was collected at $0.05 \mathrm{~V}$ and $\mathrm{R}$ represents a spectrum at the sample potential. In this configuration, negative bands (facing down) represent the production of substances, whereas positive bands (facing up) are related to their consumption. Each spectrum was originated from an average of 50 interferograms. FTIR series were collected at intervals of $0.10 \mathrm{~V}$ in the range of $0.05-1.40 \mathrm{~V}$ (binary catalysts) or $0.05-0.90 \mathrm{~V}$ (ternary ones) using a scan rate of $5 \mathrm{mV} \mathrm{s}^{-1}$ controlled by a Palm-Sens EmStat potentiostat (Houten, The Netherlands). In these experiments, $0.1 \mathrm{~mol} \mathrm{~L}^{-1} \mathrm{HClO}_{4}$ was used as supporting electrolyte in presence of $0.1,1.0$ or $3.0 \mathrm{~mol} \mathrm{~L} \mathrm{~L}^{-1}$ ethanol.

\section{Results and Discussion}

Ir-based catalysts were characterized by EDS analysis and the real composition is shown in Table 1. It is noteworthy that the real obtained atomic composition was not the one previously desired. Specifically, the Ir content is always lower that the one expressed in nominal atomic composition, suggesting that $\mathrm{IrCl}_{3}$ was not completely reduced during the synthesis. Albeit the atomic relations did not correspond exactly to those initially established, it was possible to obtain catalysts with different atomic proportions that will be named, throughout this work, as a function of their real compositions as follows: $\mathrm{Ir}_{60} \mathrm{Rh}_{40} / \mathrm{C}$; $\mathrm{Ir}_{70} \mathrm{Rh}_{30} / \mathrm{C} ; \mathrm{Ir}_{75} \mathrm{Rh}_{25} / \mathrm{C} ; \mathrm{Ir}_{55} \mathrm{Rh}_{10} \mathrm{Sn}_{35} / \mathrm{C}$ and $\mathrm{Ir}_{60} \mathrm{Rh}_{10} \mathrm{Sn}_{30} / \mathrm{C}$.

Table 1. Atomic compositions obtained by energy dispersive spectroscopy (EDS) analysis

\begin{tabular}{lccc}
\hline $\begin{array}{l}\text { Nominal atomic } \\
\text { composition / at.\% }\end{array}$ & \multicolumn{3}{c}{ Real atomic composition / at.\% } \\
\hline Ir:Rh:Sn & Ir & $\mathrm{Rh}$ & $\mathrm{Sn}$ \\
\hline $70: 30$ & $60 \pm 8.3$ & $40 \pm 8.8$ & - \\
$80: 20$ & $70 \pm 2.2$ & $30 \pm 2.2$ & - \\
$90: 10$ & $75 \pm 4.9$ & $25 \pm 4.9$ & - \\
$70: 10: 20$ & $55 \pm 1.7$ & $10 \pm 1.1$ & $35 \pm 1.9$ \\
$80: 10: 10$ & $60 \pm 2.2$ & $10 \pm 1.3$ & $30 \pm 1.8$ \\
\hline
\end{tabular}

Figure 1 shows the X-ray diffraction patterns of the binary IrRh catalysts. For all diffractograms, a wide peak is observed at nearly $25^{\circ}$, which is associated to the (002) plane of the hexagonal structure of Vulcan XC-7213,24 carbon, used as support material. Peaks at approximately 
$41^{\circ}$ and $84^{\circ}$ are ascribed to $\operatorname{Ir}(111)$, (311) planes, respectively, characteristic of the face cubic centered (fcc) structure of $\mathrm{Ir}^{24,29}$ However, neither peaks corresponding to $\operatorname{Ir}(200)$ and (220) planes are distinguished nor $\mathrm{Rh}$ diffraction peaks were detected.

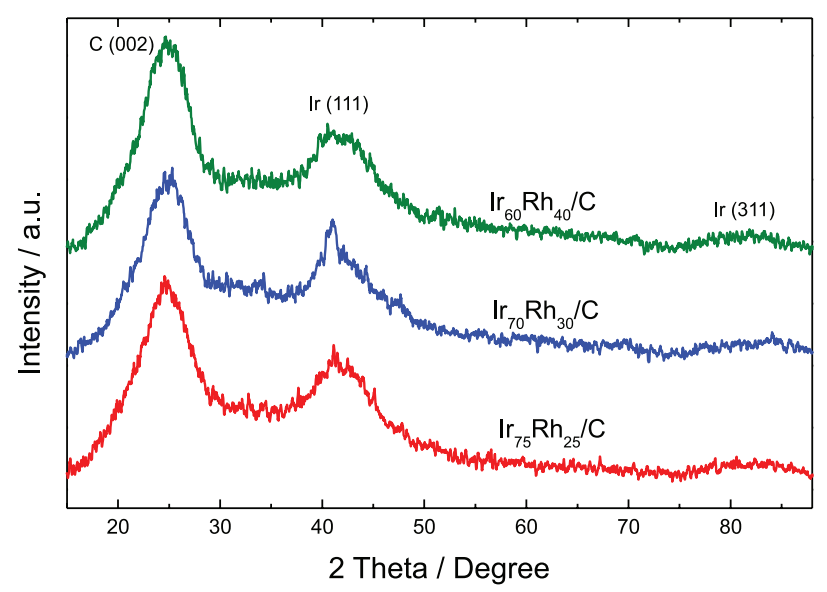

Figure 1. X-ray diffraction (XRD) patterns of $\mathrm{Ir}_{60} \mathrm{Rh}_{40} / \mathrm{C}, \mathrm{Ir}_{70} \mathrm{Rh}_{30} / \mathrm{C}$ and $\mathrm{Ir}_{75} \mathrm{Rh}_{25} / \mathrm{C}$ catalysts.
TEM images of $\mathrm{Ir}_{60} \mathrm{Rh}_{40} / \mathrm{C}, \mathrm{Ir}_{70} \mathrm{Rh}_{30} / \mathrm{C}$ and $\mathrm{Ir}_{75} \mathrm{Rh}_{25} / \mathrm{C}$ catalysts are shown in Figures $2 \mathrm{a}-2 \mathrm{c}$, respectively. In general, the micrographs for binary catalysts present very small metallic nanoparticles (dark spots in the image) on the carbon support (lighter regions), with an uneven distribution. The presence of regions with large agglomerates is also observed, as reported in the literature, ${ }^{20,25}$ albeit Cao et al. ${ }^{25}$ assume that the agglomeration of nanoparticles was associated with a rapid reduction process caused by the addition of $\mathrm{NaBH}_{4}$.

High resolution images of $\operatorname{Ir}_{60} \mathrm{Rh}_{10} \mathrm{Sn}_{30} / \mathrm{C}$ and elemental mapping are present in Figures $2 \mathrm{~d}$ and $2 \mathrm{e}$, respectively. Figure 2e demonstrates that all metals are present in the nanoparticles with a distribution nearly uniform. Namely, $\mathrm{Ir}, \mathrm{Rh}$ and $\mathrm{Sn}$ are present through all the nanoparticle, with Sn being present even on those darker regions of the micrograph (compare with Figure 2d), suggesting that $\mathrm{Sn}$ may be more spread throughout the nanoparticles.

Figure 3 shows cyclic voltammograms for pure Ir (electrodeposited), IrRh/C and IrRhSn/C in different compositions, in the supporting electrolyte (dashed lines
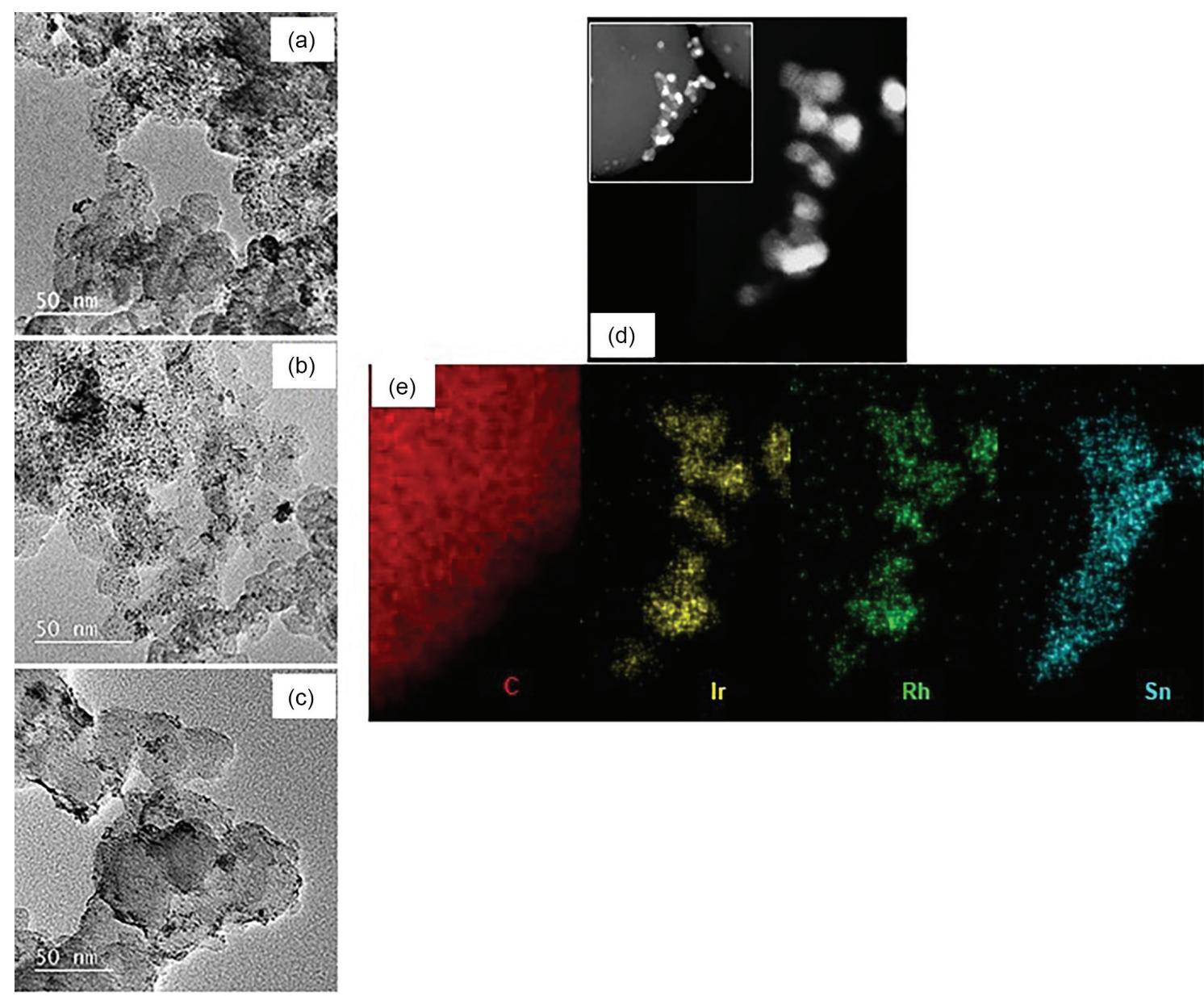

Figure 2. TEM images of (a) $\mathrm{Ir}_{60} \mathrm{Rh}_{40} / \mathrm{C}$, (b) $\mathrm{Ir}_{70} \mathrm{Rh}_{30} / \mathrm{C}$ and (c) $\mathrm{Ir}_{75} \mathrm{Rh}_{25} / \mathrm{C}$ catalysts; (d) HRTEM image of $\mathrm{Ir}_{60} \mathrm{Rh}_{10} \mathrm{Sn}_{30} / \mathrm{C}$ and (e) elemental mapping images of C (red), Ir (yellow), Rh (green) and Sn (blue). 
in black) and in the presence of ethanol (full lines in red), both at concentrations of $0.1 \mathrm{~mol} \mathrm{~L}^{-1}$. In all cases, the first voltammetric cycle is presented for each catalyst. The ethanol electrooxidation over pure Ir starts at ca. $0.63 \mathrm{~V}$ and shows an oxidation peak at $1.06 \mathrm{~V}$. In the reverse sweep, there is a reactivation of the surface and a new oxidation peak appears at $0.70 \mathrm{~V}$.

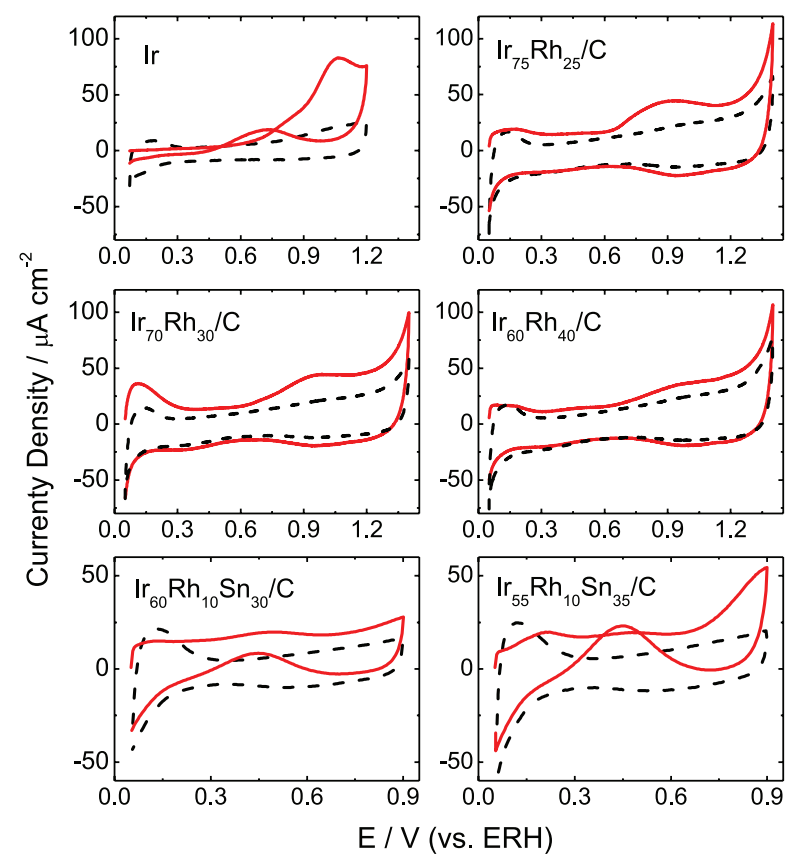

Figure 3. Cyclic voltammograms obtained for $\mathrm{Ir}, \mathrm{IrRh} / \mathrm{C}$ and $\mathrm{IrRhSn} / \mathrm{C}$ catalysts in: (---) $0.1 \mathrm{~mol} \mathrm{~L}^{-1} \mathrm{HClO}_{4}$ and (-) $0.1 \mathrm{~mol} \mathrm{~L}^{-1} \mathrm{HClO}_{4}+$ $0.1 \mathrm{~mol} \mathrm{~L}^{-1} \mathrm{CH}_{3} \mathrm{CH}_{2} \mathrm{OH}$, at $0.05 \mathrm{~V} \mathrm{~s}^{-1}$. Compositions indicated in the figures.

For binary catalysts, the ethanol oxidation starts at ca. $0.63 \mathrm{~V}$ with discrete current densities that decrease with increasing $\mathrm{Rh}$ content. $\mathrm{Ir}_{75} \mathrm{Rh}_{25} / \mathrm{C}$ shows a single oxidation peak around $0.90 \mathrm{~V}$ tending to disappear as the composition is enriched by $\mathrm{Rh}\left(\mathrm{Ir}_{60} \mathrm{Rh}_{40} / \mathrm{C}\right)$. In contrast to the behavior observed for pure Ir, reactivation currents cannot be detected on these catalysts, which suggests that (i) there are few adsorbed species that could be oxidized in the reverse sweep and/or (ii) the cathodic current relative to the reduction of Rh oxides during the reverse sweep prevails over eventual oxidation currents.

For $\mathrm{Ir}_{60} \mathrm{Rh}_{10} \mathrm{Sn}_{30} / \mathrm{C}$ and $\mathrm{Ir}_{55} \mathrm{Rh}_{10} \mathrm{Sn}_{35} / \mathrm{C}$, there are no discernible oxidation peaks during the upward scan, which is probably due to the low potential limit (a potential of $0.9 \mathrm{~V}$ was used to avoid the dissolution of Sn that takes place at higher potentials). However, soon after the inhibition is observed in hydrogen region, a consistent oxidation plateau is observed in all the range of potentials. Also, the rising of reactivation currents in the backward scan is noted, as already seen for pure Ir.
Next, $\operatorname{IrRh} / \mathrm{C}$ and IrRhSnC electrocatalysts were evaluated as a function of the increase of the ethanol concentration and the corresponding results are presented in Figures 4 and 5 for binary and ternary catalysts, respectively. Once the voltammetric profiles of $\mathrm{Ir}_{75} \mathrm{Rh}_{25} / \mathrm{C}$ and $\operatorname{Ir}_{70} \mathrm{Rh}_{30} / \mathrm{C}$ are very similar (see Figure 3), while $\mathrm{Ir}_{60} \mathrm{Rh}_{40} / \mathrm{C}$ is detrimental for EOR, the intermediate composition was chosen to illustrate the behavior of the binary series and compared with the ternary catalysts.

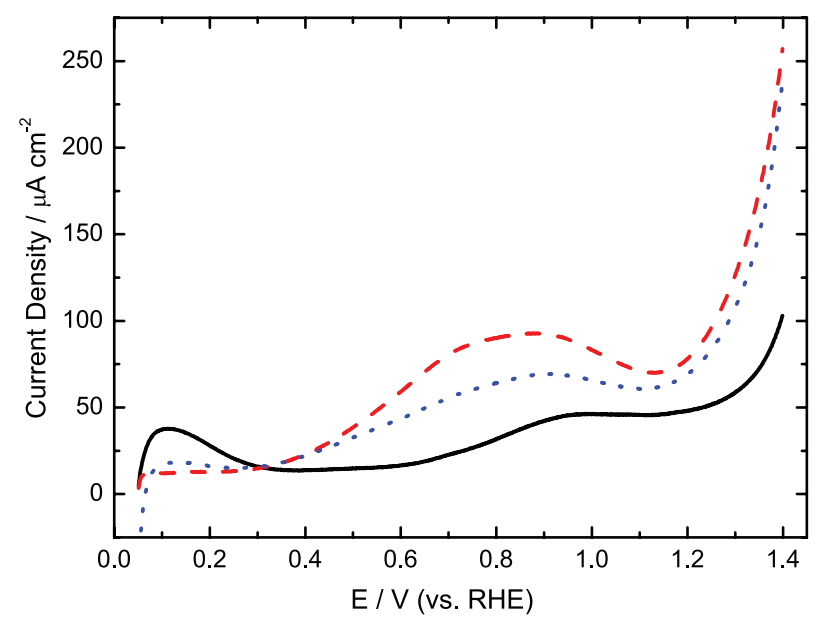

Figure 4. Anodic curves obtained for the $\mathrm{Ir}_{70} \mathrm{Rh}_{30} / \mathrm{C}$ catalysts for different concentrations of ethanol: (-) $0.1 \mathrm{~mol} \mathrm{~L}^{-1},(\cdots) 1.0 \mathrm{~mol} \mathrm{~L}^{-1}$ and (---) $3.0 \mathrm{~mol} \mathrm{~L}^{-1}$, at $0.05 \mathrm{~V} \mathrm{~s}^{-1}$.

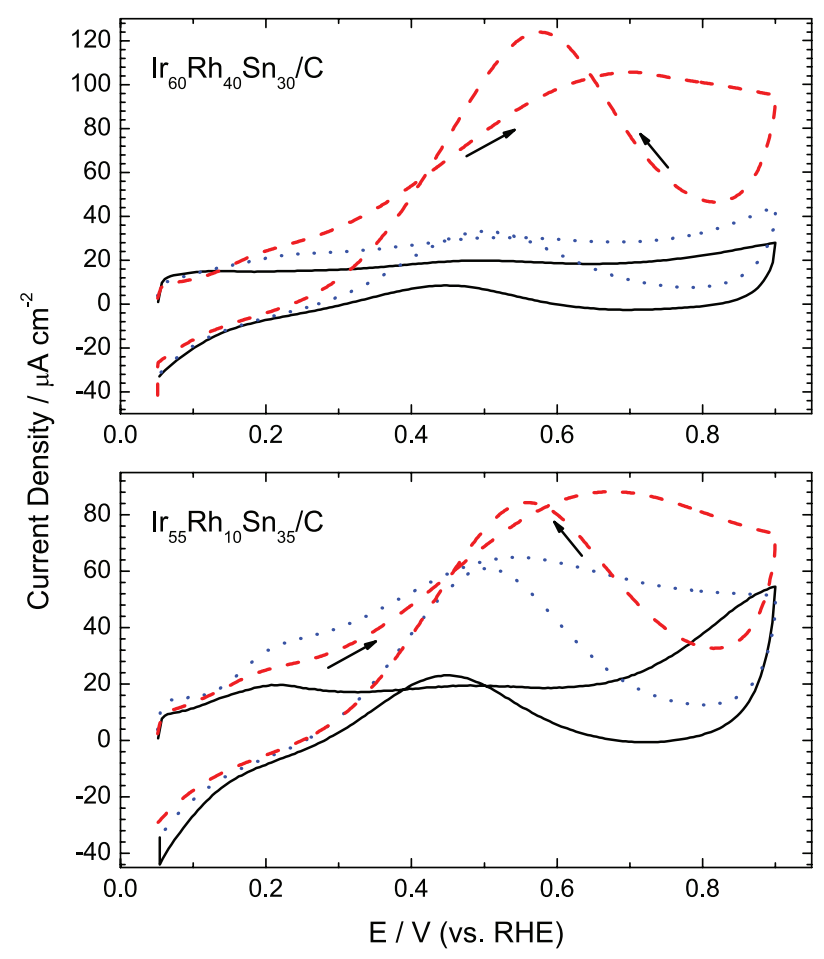

Figure 5. Cyclic voltammograms obtained for the ternary catalysts (compositions are indicated in the figures) for different concentrations of ethanol: (-) $0.1 \mathrm{~mol} \mathrm{~L}^{-1},(\cdots \cdot) 1.0 \mathrm{~mol} \mathrm{~L}^{-1}$ and (---) $3.0 \mathrm{~mol} \mathrm{~L}^{-1}$, at $0.05 \mathrm{~V} \mathrm{~s}^{-1}$. 
Figure 4 shows the voltammetric curves (anodic scans) obtained at concentrations of $0.1,1.0$ and $3.0 \mathrm{~mol} \mathrm{~L}^{-1}$ of ethanol for $\mathrm{Ir}_{70} \mathrm{Rh}_{30} / \mathrm{C}$. Here it is important to note that the cathodic scans for the three ethanol concentrations are not shown since no reactivation currents are observed (see Figure 3). Figure 4 shows that the increase of the ethanol concentration leads to an increase in current density. This increase is probably related to a greater amount of electroactive species in solution, causing a greater adsorption on the electrode surface. This effect can be confirmed by analyzing the potential region between 0.05 and $0.25 \mathrm{~V}$, in which the hydrogen adsorption region becomes progressively blocked as the ethanol concentration increases.

Figure 5 shows the ethanol oxidation at $0.1,1.0$ and $3.0 \mathrm{~mol} \mathrm{~L}^{-1}$ ethanol concentrations for $\mathrm{Ir}_{60} \mathrm{Rh}_{10} \mathrm{Sn}_{30} / \mathrm{C}$ and $\mathrm{Ir}_{55} \mathrm{Rh}_{10} \mathrm{Sn}_{35} / \mathrm{C}$. A major difference compared to $\mathrm{Ir}_{70} \mathrm{Rh}_{30} / \mathrm{C}$ is the presence of reactivation currents, already commented for $0.1 \mathrm{~mol} \mathrm{~L}^{-1}$ ethanol. However, these currents become progressively more important as the concentration of ethanol is increased. This probably happens because more species are accumulated over the surface during the upward scan. Furthermore, the surface richer in Ir seems to be more sensitive to the presence of ethanol because the oxidation currents for $\operatorname{Ir}_{55} \mathrm{Rh}_{10} \mathrm{Sn}_{35} / \mathrm{C}$ are more similar to each other in the concentrations of 1.0 and $3.0 \mathrm{~mol} \mathrm{~L}^{-1}$ than their respective counterparts for $\operatorname{Ir}_{60} \mathrm{Rh}_{10} \mathrm{Sn}_{30} / \mathrm{C}$. This behavior is particularly important taking into account that practical devices, as direct ethanol fuel cells, will require high concentrations of ethanol.

The behavior of Figure 5 suggests that when proper amounts of the metals are used, there is a gain in the tolerance to ethanol, but a voltammetric analysis alone does not allow to understand what is the role played by each metal during the ethanol electrooxidation. Hence, a more detailed analysis is required to identify the molecular nature of the species that are formed during the reaction and to correlate this information with the voltammetric behavior observed. Such analysis, based on in situ FTIR spectroscopy, will be done in the next section.

\section{Following the products of the ethanol oxidation reaction by in situ FTIR}

In order to understand the differences in the electrocatalytic activity during ethanol electrooxidation of the compositions $\mathrm{Ir}_{70} \mathrm{Rh}_{30}, \mathrm{Ir}_{55} \mathrm{Rh}_{10} \mathrm{Sn}_{35}$ and $\mathrm{Ir}_{60} \mathrm{Rh}_{10} \mathrm{Sn}_{30}$ from a molecular perspective, in situ FTIR experiments were performed in the three selected compositions and in the ethanol concentrations of $0.1,1.0$ and $3.0 \mathrm{~mol} \mathrm{~L}^{-1}$, these results are presented in Figure 6. The absorption bands observed during the ethanol electrooxidation are already described by the literature and are summarized in Table 2. ${ }^{12}$

Here the analysis of the oxidation pathways of ethanol will be limited to the bands at $2343 \mathrm{~cm}^{-1}$ (relative to the production of $\mathrm{CO}_{2}$ ) and at $1280 \mathrm{~cm}^{-1}$ (referent to the production of acetic acid). Bands at 1720 and $1357 \mathrm{~cm}^{-1}$ designate vibrational modes of functional groups that are present on both acetic acid and acetaldehyde, hence, their signals cannot be separated. The band relative to linearlybonded CO appears ca. $2050 \mathrm{~cm}^{-1}$, but here it was not analyzed in quantitative terms, once rough surfaces (as in present case) interfere in the absorption coefficients, and this effect is particularly dramatic for adsorbed species..$^{30}$

Table 2. Bands related to the species formed from the ethanol electrooxidation

\begin{tabular}{lc}
\hline Frequency $/ \mathrm{cm}^{-1}$ & Species and chemical group \\
\hline 2343 & $\mathrm{CO}_{2}(\mathrm{O}=\mathrm{C}=\mathrm{O}$ asymmetric stretching $)$ \\
2050 & $\mathrm{CO}_{\mathrm{L}}(\mathrm{C}-\mathrm{O}$ stretching of linearly adsorbed $\mathrm{CO})$ \\
1720 & $\mathrm{C}=\mathrm{O}$ stretching \\
1280 & acetic acid $(\mathrm{C}=\mathrm{O}$ stretching of acetic acid in solution $)$ \\
1357 & acetaldehyde / acetic acid $($ symmetric angular \\
& deformation $\left.\mathrm{CH}_{3}\right)$ \\
\hline
\end{tabular}

Adapted from reference. ${ }^{12}$

Turning back our attention to Figure 6, the left column shows the FTIR series of $\mathrm{Ir}_{70} \mathrm{Rh}_{30}$ for three concentrations of ethanol. From the series, some important findings can be extracted. First, the CO band $\left(2050 \mathrm{~cm}^{-1}\right)$ is never observed. Such lack could suggest that $\mathrm{C}-\mathrm{C}$ bond breaking is not taking place over the binary catalyst, which seems to contradict the fact that $\mathrm{Rh}$ favors the breaking of $\mathrm{C}-\mathrm{C}$ bonds, as already argued. ${ }^{9-11}$ However, $\mathrm{CO}_{2}$ signal is visible over a wide range of potentials and $\mathrm{CO}$ (whose formation from ethanol is illustrated in equation 1) is the sole precursor of $\mathrm{CO}_{2}$ during ethanol oxidation:

$$
\begin{aligned}
& \mathrm{CH}_{3} \mathrm{CH}_{2} \mathrm{OH} \rightarrow \mathrm{Pt}-\mathrm{CO}_{\text {ads }}+\mathrm{Pt}-\mathrm{CH}_{3}+3 \mathrm{H}^{+}+3 \mathrm{e}^{-} \\
& \mathrm{Pt}-\mathrm{CO}_{\text {ads }}+\mathrm{Pt}-\mathrm{OH}_{\text {ads }} \rightarrow \mathrm{CO}_{2}+\mathrm{H}^{+}+\mathrm{e}^{-} \\
& \mathrm{CH}_{3} \mathrm{CH}_{2} \mathrm{OH}+\mathrm{Pt}-\mathrm{OH}_{\text {ads }} \rightarrow \mathrm{CH}_{3} \mathrm{COOH}+3 \mathrm{H}^{+}+3 \mathrm{e}^{-}
\end{aligned}
$$

Hence, it seems more plausible that $\mathrm{CO}$ is produced along the upward scan, but its consumption rate (i.e., the production of $\mathrm{CO}_{2}$, illustrated in equation 2 , in which $-\mathrm{OH}_{\mathrm{ads}}$ stands for a hydroxyl radical produced from water) is high enough to prevent the $\mathrm{CO}$ accumulation over the $\mathrm{Ir}_{70} \mathrm{Rh}_{30}$ surface. That finding suggests a fair tolerance to $\mathrm{CO}$, a result that brings important implications in the design of electrocatalysts for fuel cells fed by alcohols. 

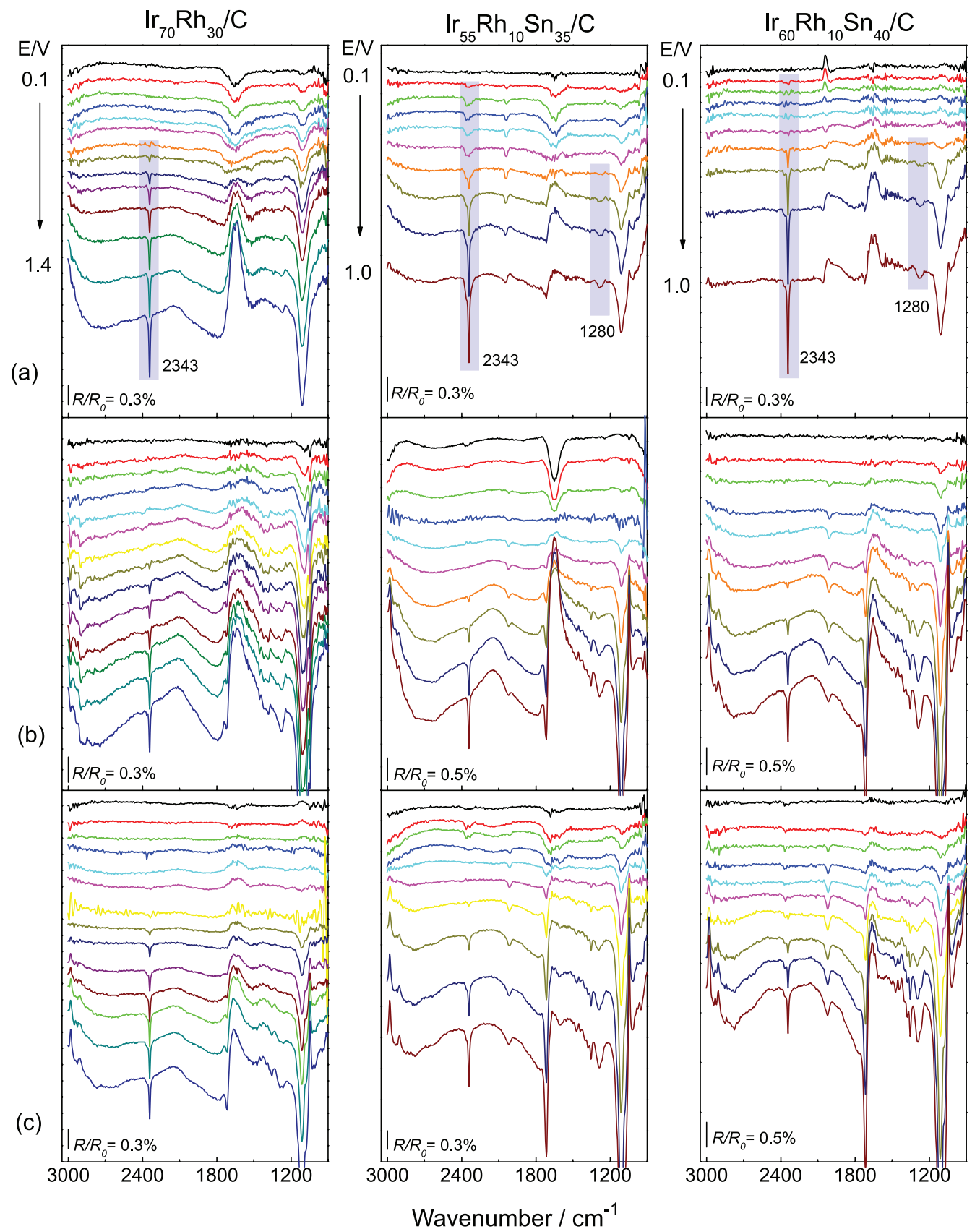

Figure 6. In situ FTIR spectra obtained in three concentrations of $\mathrm{CH}_{2} \mathrm{CH}_{3} \mathrm{OH}$ : (a) $0.1 \mathrm{~mol} \mathrm{~L}^{-1}$, (b) $1 \mathrm{~mol} \mathrm{~L}^{-1}$ and (c) 3 mol L-1 reference spectra taken at $0.05 \mathrm{~V}$. Potentials and compositions are indicated in the figure.

Another important aspect is the absence of acetic acid in the top left panel, which suggests that $\mathrm{Ir}_{70} \mathrm{Rh}_{30}$ is selective to the production of $\mathrm{CO}_{2}$, at least in the lower ethanol concentration. This finding is also in line with previous works that show Rh helps to split C-C bonds. ${ }^{9-11}$ When higher ethanol concentrations are used, acetic acid is formed (whose production is represented in equation 3), but only at high potentials (see the growing of the band at ca. $1280 \mathrm{~cm}^{-1}$, whose details are provided later in Figure 7), reinforcing the selectivity towards the production of $\mathrm{CO}_{2}$.
When these results are compared to those in Figure 3, they suggest that the low oxidation currents observed for binary IrRh catalysts are mainly caused by a slow production of $\mathrm{CO}_{2}$, but since $\mathrm{CO}$ is never accumulated over these surfaces, the data strongly suggest that the rate-determining step (rds) during EOR for IrRh is the adsorption of $\mathrm{CO}$, i.e., the slow $\mathrm{CO}$ accumulation over the surface prevents high oxidation rates to be attained. Eventually, acetic acid shows an important production at potentials higher than $1.1 \mathrm{~V}$, but in this extreme oxidative condition, the analysis of the role played by the catalyst 
becomes impractical because any adsorption step is hindered by fragments of water that populate the surface (possibly Pt-OH $\mathrm{OH}_{\text {ads }}$ ).

The situation is different when the ternary compositions are analyzed (central and right panels in Figure 6). First, the $\mathrm{CO}$ band is present for both compositions, while the $\mathrm{CO}_{2}$ signal is sensibly more intense than for $\mathrm{Ir}_{70} \mathrm{Rh}_{30}$. This behavior indicates that the production of $\mathrm{CO}_{2}$ is faster in presence of $\mathrm{Sn}$. But the $\mathrm{C}-\mathrm{C}$ bond breaking also seems to be affected because $\mathrm{CO}$ bands are quite discernible along the potential scan. This higher oxidative potential of the ternary catalysts compared to $\mathrm{Ir}_{70} \mathrm{Rh}_{30}$ seems good news at a first glance, but on the other hand, the presence of $\mathrm{Sn}$ is detrimental for the selectivity of the surface. Namely, for both IrRhSn compositions, acetic acid band is far more developed than for $\operatorname{Ir}_{70} \mathrm{Rh}_{30}$, even for the lower ethanol concentration. By comparing the ternary catalysts among them, the composition richer in Sn (40\%) is the one that produces more acetic acid.
As an attempt to deepen the information discussed in Figure 6, the areas of $\mathrm{CO}_{2}$ and acetic acid bands were integrated as a function of the potential, and then normalized by the corresponding ECSAs of the catalysts, allowing the comparison. These data are expressed in Figure 7 for the three compositions chosen and for all ethanol concentrations analyzed.

Two noteworthy aspects of Figure 7 are: $(i)$ the dependence of the oxidation pathways with the composition (particularly the presence of Sn) and (ii) with the ethanol concentration. Starting our analysis by the $\mathrm{CO}_{2}$ bands, they are relatively intense for $\mathrm{Ir}_{70} \mathrm{Rh}_{30}$, but only at high potentials, which include a range not visited by the ternary ones. Notably, $\mathrm{CO}_{2}$ bands emerge and grow in the same potential range of the oxidation currents observed in the voltammograms of Figure 4 (from $0.7 \mathrm{~V}$ onwards). This observation suggests that its production is at least partially responsible for the oxidation currents observed for $\operatorname{Ir}_{70} \mathrm{Rh}_{30}$. When the

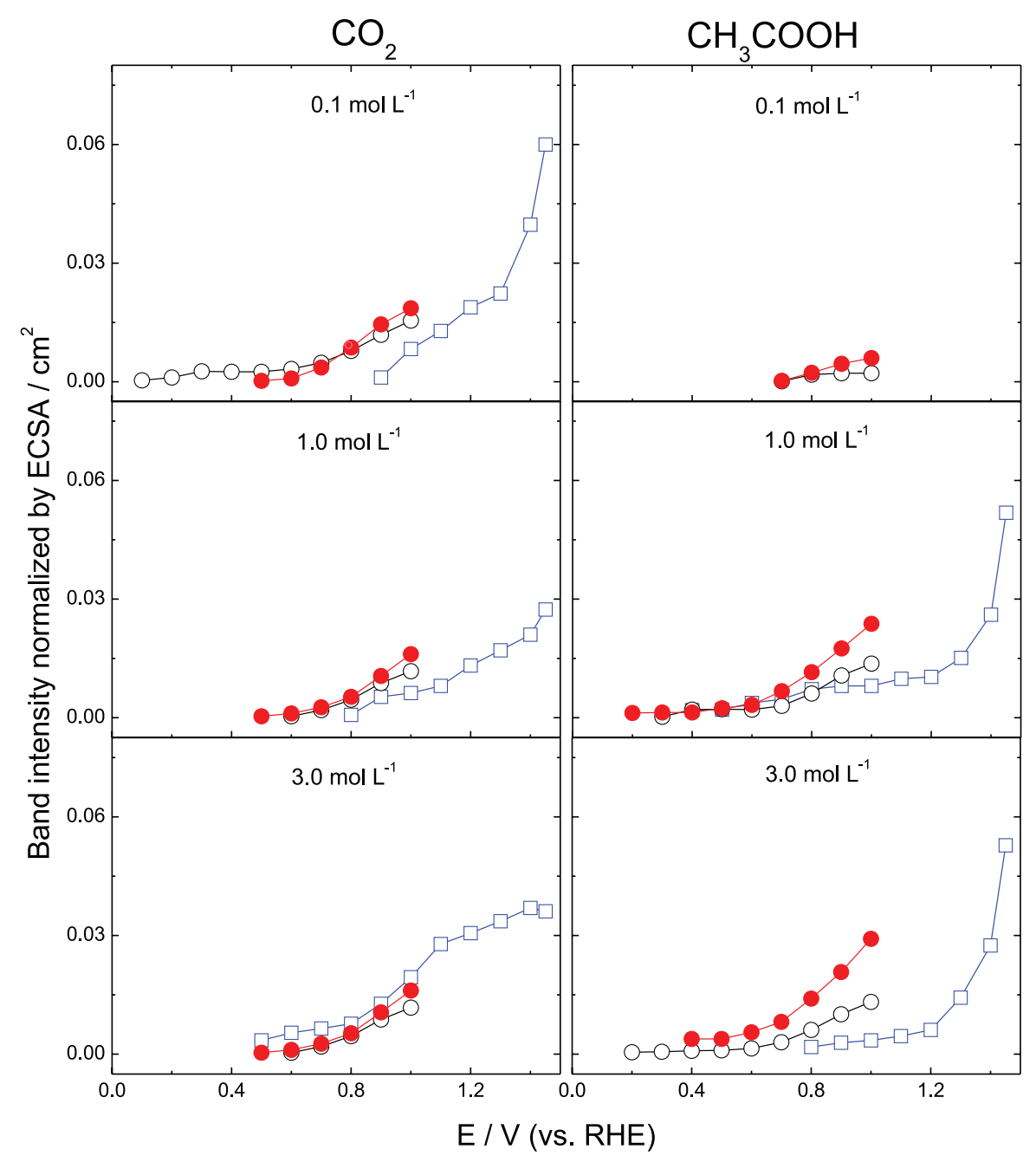

Figure 7. Band intensities of $\mathrm{CO}_{2}$ and $\mathrm{CH}_{3} \mathrm{COOH}$ as a function of the potential, extracted from spectra of Figure 6, for: $(\square) \mathrm{Ir}_{70} \mathrm{Rh}_{30} ;(\mathrm{O}) ; \mathrm{Ir}_{55} \mathrm{Rh}_{10} \mathrm{Sn}_{35}$ and (O) $\mathrm{Ir}_{60} \mathrm{Rh}_{10} \mathrm{Sn}_{30}$. Ethanol concentrations are indicated in the figure. 
analysis is limited to $1.0 \mathrm{~V}$, the production of $\mathrm{CO}_{2}$ is anticipated by Sn, especially at ethanol concentrations of 0.1 and $1.0 \mathrm{~mol} \mathrm{~L}^{-1}$. As already commented, the rds for $\mathrm{Ir}_{70} \mathrm{Rh}_{30}$ apparently is the adsorption of the ethanol. Hence, when the ethanol concentration is increased to $3.0 \mathrm{~mol} \mathrm{~L}^{-1}$, the number of available species near the surface grows accordingly, and the slow steps of adsorption are favored. Consequently, the production of $\mathrm{CO}_{2}$ becomes more important. For the ternary compositions, the production of $\mathrm{CO}_{2}$ seems virtually independent on the ethanol concentration (see the left column of Figure 7). In this case, it seems that the presence of $\mathrm{Sn}$ causes a third body effect that restrains the rupture of $\mathrm{C}-\mathrm{C}$ bonds, as recently demonstrated for glycerol on $\mathrm{Pt}(100)$ preferentially oriented nanoparticles. ${ }^{31}$ If we assume that the same effect is operative in present case, those sites occupied for $\mathrm{Sn}$ are unable to adsorb ethanol. Hence, an increase in ethanol concentration favors the formation of acetic acid. This is a pathway that is believed to be less site-demanding than the production of the pair $\mathrm{CO}-\mathrm{CO}_{2}$, i.e., the production of acetic acid requires fewer sites to be produced once is believed that ethanol is adsorbed via a single carbon to be oxidized to acetic acid, while the formation of $\mathrm{CO}$ requires a scission of $\mathrm{C}-\mathrm{C}$ bonds, that only can be attained when both carbons are attached to the surface.

In a paper that investigates the effects of ethanol concentration over Pt, Camara and Iwasita ${ }^{32}$ demonstrate that the gain in terms of current densities is only observed up to mild concentrations (typically, the maximum activity is observed for ethanol concentrations of $0.5 \mathrm{~mol} \mathrm{~L}^{-1}$ ). Above this concentration, the surface experiences a self-poisoning effect. By using in situ FTIR, the authors explain this inhibition in terms of a competition between the organic itself and its reaction partner (water or oxides stemming from it). ${ }^{32}$ When high alcohol concentrations are present, the high corresponding surface coverages inhibit the water coadsorption. Assuming that some of the important electro-oxidation pathways, as the production of acetic acid and $\mathrm{CO}_{2}$ are reactions governed by a LangmuirHinshelwood mechanism, this excess of adsorbates from ethanol prevents those steps of electrooxidation. Such self-inhibition was also demonstrated for analogous molecules, as acetaldehyde ${ }^{33}$ and glycerol. ${ }^{34}$

When Figures 6 and 7 are analyzed in light of the voltammetric behavior of ternary catalysts and based on the comments of the last paragraph, the fact that higher ethanol concentrations favor the formation of acetic acid in these materials (see the bands at $1280 \mathrm{~cm}^{-1}$ in Figure 6 and the right column in Figure 7) seems to justify the growth of the oxidation currents observed for both IrRhSn compositions (Figure 5). On the other hand, $\mathrm{CO}_{2}$ production is virtually insensitive to the ethanol concentration, and cannot be correlated with the higher currents observed for 1 and $3 \mathrm{~mol} \mathrm{~L}^{-1}$ in Figure 5.

Summarizing, IrRh surfaces are able to promote the scission of $\mathrm{C}-\mathrm{C}$ bonds during the ethanol electrooxidation, but the slow formation of $\mathrm{CO}$ (probably caused by a slow adsorption of ethanol) prevents a strong production of $\mathrm{CO}_{2}$. Consequently, IrRh surfaces seem to be selective to the production of $\mathrm{CO}_{2}$ (from ethanol), but the global catalytic activity is poor. On the other hand, IrRhSn surfaces present important oxidation currents at relative low potentials, but when the pathways are analyzed, these currents arise as a consequence of a major production of acetic acid.

Our results indicate that Ir-based surfaces are promising candidates to be used in fuel cells fed by alcohols, provided that cocatalysts which favor the steps of adsorption and disruption of the chain are used in the appropriate amounts. To do so, more studies with a molecular approach are needed, allowing a correlation between the global electrocatalytic activity and the electrooxidation pathways.

\section{Conclusions}

IrRh binary electrocatalysts are selective to the production of $\mathrm{CO}_{2}$ from ethanol, but the catalytic activity is poor. In situ FTIR results performed on three concentrations of ethanol suggest that this poor output is due to a slow adsorption of ethanol, being probably the rate determining step during the ethanol electrooxidation. On the other hand, when ternary IrRhSn catalysts are used, higher electrooxidation currents are perceived if compared to IrRh surfaces, illustrating the influence of $\mathrm{Sn}$ on the ethanol eletrooxidation. FTIR analysis show that the selectivity towards the $\mathrm{CO}_{2}$ pathway is lost, and that the higher catalytic activity is justified by a growing production of acetic acid. Our results indicate that Ir-based surfaces are promising candidates to be used in fuel cells fed by alcohols and that more studies with a molecular approach are needed, allowing a correlation between the global electrocatalytic activity and the electrooxidation pathways.

\section{Acknowledgments}

F. R. P. da Silva and L. C. Silva-Junior are indebted to CAPES for fellowships. M. J. Giz and G. A. Camara acknowledge financial assistance from CNPq (grant Nos. 309176/2015-8, 406779/2016-3 and 308821/2016-5), FINEP and FUNDECT. We also thank LNNano-CNPEM (Campinas-SP, Brazil) and CAQI (IQSC, São Carlos-SP, Brazil) for the use of the electron microscopy facilities. This study was financed in part by the Coordenação de 
Aperfeiçoamento de Pessoal de Nível Superior (CAPES), Brasil, finance code 001.

\section{References}

1. Vigier, F.; Coutanceau, C.; Perrard, A.; Belgsir, E. M.; Lamy, C.; J. Appl. Electrochem. 2004, 34, 439.

2. Camara, G. A.; de Lima, R. B.; Iwasita, T.; Electrochem. Commun. 2004, 6, 812 .

3. Antolini, E.; Mater. Chem. Phys. 2003, 78, 563.

4. Lamy, C.; Belgsir, E. M.; Leger, J. M.; J. Appl. Electrochem. 2001, 31, 799.

5. Zhou, W. J.; Zhou, Z. H.; Song, S. Q.; Li, W. Z.; Sun, G. Q.; Tsiakaras, P.; Xin, Q.; Appl. Catal., B 2003, 46, 273.

6. Antolini, E.; J. Power Sources 2007, 170, 1.

7. Brown, L. F.; Int. J. Hydrogen Energy 2001, 26, 381.

8. Dohle, H.; Schmitz, H.; Bewer, T.; Mergel, J.; Stolten, D.; J. Power Sources 2002, 106, 313.

9. Gupta, S. S.; Datta, J.; J. Electroanal. Chem. 2006, 594, 65.

10. Bergamaski, K.; Nart, F. C.; Gonzalez, E. R.; Electrochim. Acta 2008, 53, 4396 .

11. de Souza, J. P. I.; Queiroz, S. L.; Bergamaski, K.; Gonzalez, E. R.; Nart, F. C.; J. Phys. Chem. B 2002, 106, 9825.

12. Vigier, F.; Coutanceau, C.; Hahn, F.; Belgsir, E. M.; Lamy, C.; J. Electroanal. Chem. 2004, 563, 81.

13. Silva-Junior, L. C.; Maia, G.; Passos, R. R.; Souza, E. A.; Camara, G. A.; Giz, M. J.; Electrochim. Acta 2013, 112, 612.

14. Ribeiro, J.; dos Anjos, D. M.; Kokoh, K. B.; Coutanceau, C.; Léger, J. M.; Olivi, P.; de Andrade, A. R.; Tremiliosi-Filho, G.; Electrochim. Acta 2007, 52, 6997.

15. Takasu, Y.; Yoshinaga, N.; Sugimoto, W.; Electrochem. Commun. 2008, 10, 668.

16. Qiao, J. L.; Lin, R.; Li, B.; Ma, J. X.; Liu, J. S.; Electrochim. Acta 2010, 55, 8490.

17. Zheng, J. S.; Wang, X. Z.; Qiao, J. L.; Yang, D. J.; Li, B.; Li, P.; Iv, H.; Ma, J. X.; Electrochem. Commun. 2010, 12, 27.

18. Liu, B.; Chia, Z.-W.; Cheng, C.-H.; Lee, J.-Y.; Energy Fuels 2011, 25, 3135.
19. Silva, J. C. M.; Anea, B.; de Souza, R. F. B.; Assumpção, M. H. M. T.; Calegaro, M. L.; Neto, A. O.; Santos, M. C.; J. Braz. Chem. Soc. 2013, 24, 1553.

20. Du, W.; Wang, Qi.; Saxner, D.; Deskins A. A.; Su, D.; Krzanowski, J. E.; Frenkel, A. I.; Teng, X. J.; J. Am. Chem. Soc. 2011, 133, 15172.

21. El Sawy, E. N.; Birss, V. I.; J. Mater. Chem. 2009, 19, 8244.

22. Vot, S. L.; Roué, L.; Bélanger, D.; Electrochim. Acta 2012, 59, 49.

23. Tacconi, N. R.; Lezna, R. O.; Hahn, F.; Lamy, C.; J. Electroanal. Chem. 1994, 379, 329.

24. Tayal, J.; Rawat, B.; Basu, S.; Int. J. Hydrogen Energy 2011, 36, 14884.

25. Cao, L.; Sun, G.; Li, H.; Xin, Q.; Electrochem. Commun. 2007, 9, 2541.

26. Fiévet F.; Lagier, J. P.; Figlarz, M.; MRS Bull. 1989, 14, 29.

27. Viau, G.; Fiévet-Vicent, F.; Fiévet, F.; Solid State Ionics 1996, 84, 259.

28. Pastrián, F. A. C.; da Silva, A. G. M.; Dourado, A. H. B.; Batista, A. P. L.; de Oliveira-Filho, A. G. S.; Quiroz, J.; de Oliveira, D. C.; Camargo, P. H. C.; de Torresi, S. I. C.; ACS Catal. 2018, 8,6265 .

29. Montero, M. A.; Fernández, J. L.; de Chialvo, M. R. G.; Chialvo, A. C.; J. Phys. Chem. C 2013, 117, 25269.

30. Giz, M. J.; Camara, G. A.; Maia, G.; Electrochem. Commun. 2009, 11, 1586.

31. Araujo, H. R.; Zanata, C. R.; Teixeira-Neto, E.; de Lima, R. B.; Batista, B. C.; Giz, M. J.; Camara, G. A.; Electrochim. Acta 2019, 297, 61.

32. Camara, G. A.; Iwasita, T.; J. Electroanal. Chem. 2005, 578, 315.

33. Farias, M. J. S.; Camara, G. A.; Tanaka, A. A.; Iwasita, T.; J. Electroanal. Chem. 2007, 600, 236.

34. Gomes, J. F.; Martins, C. A.; Giz, M. J.; Tremiliosi-Filho, G.; Camara, G. A.; J. Catal. 2013, 301, 154.

Submitted: February 7, 2019 Published online: April 25, 2019 